\title{
Sosyal Bilgiler Öğretmen Adaylarının Kimlik ve Kültür Kavramlarına Yönelik Metafor Algiları
}

\section{Perspectives on Social Studies Teacher Candidates' Metaphor Perceptions for Culture and Identity Concept}

\author{
Sule ERDILMEN OCAK \\ Atatürk üniversitesi, Kazım Karabekir Eğitim Fakültesi Türkçe ve Sosyal Bilimler Eğitimi Bölümü \\ s.erdilmen@atauni.edu.tr \\ Erol ÇIYYEM \\ Kastamonu Üniversitesi, Eğitim Fakültesi, Eğitimin Sosyal, Kültürel ve Felsefi Temelleri \\ eciydem@kastamonu.edu.tr \\ Esra MINDIVANLİ AKDOĞAN* \\ Atatürk üniversitesi, Kazım Karabekir Eğitim Fakültesi Türkçe ve Sosyal Bilimler Eğitimi Bölümü \\ emindivanli@atauni.edu.tr
}

Atıf: Edilmen-Ocak, Ş., Çiğdem, E., \& Mindivanlı-Akdoğan, E. (2017). Sosyal Bilgiler Öğretmen Adaylarının Kimlik ve Kültür Kavramlarına Yönelik Metafor Algıları. E-Kafkas Eğitim Araştırmaları Dergisi, 4(3), 59-71.

\section{Özet}

Kimlik, "İnsanların kim olduklarıyla ve toplumsal dünyayla ilgili olarak iletişim ve dil aracıllğıyla kurdukları düşünceler bütünü" șeklinde tanımlanmaktadır. Farklı birç̧ok tanımı yapılan kültür ise "bir topluluğun yaşamını sürdürmesinde uyum ve dayanışmayı sağlayacak, kişiler arasında iletişimi kuracak kurumları; yaşamı anlamlandırırken başvurulacak değerler, kurallar ve inançlar dizgesini içeren yapı" olarak ifade edilmektedir. Bu kavramlar toplumsal yaşamda bireylere aidiyetlik duygusu kazandıran başlıca faktörler arasındadır. Nitekim bu çalışmada, üniversite öğrencilerinin "kimlik ve kültür" kavramlarına yönelik algıları ve bu algılarında hangi kaynakların etkili olduğu, onların söz konusu kavramlara yönelik geliştirmiş oldukları metaforlar aracılığıyla belirlenmeye çalıșılmıștır. Metaforlar, soyut kavramların zihinde somutlaştırılması ve görselleştirilmesini sağlamakta ve böylece öğrenilen bilgilerin akılda daha uzun süre kalmasını ve daha kolay hatırlanmasını sağlayarak öğrenme motivasyonunu artırmaktadır. Bu bağlamda soyut birer kavram olan "kültür ve kimlik" hakkında geliştirilmesi beklenen metaforlar, bu kavramlara yönelik algıyı ve bu algının oluşumundaki muhtemel sebepleri ortaya koyacaktır. Araştırman in örneklemini, 2013-2014 eğitim-öğretim yılında, Atatürk Üniversitesi Kazım Karabekir Eğitim Fakültesi, Sosyal Bilgiler Öğretmenliği bölümünde I., II., III. ve IV. sınıflarda öğrenim gören öğrenci oluşturmaktadır. Verilerin toplanmasında araştırmacı tarafından geliştirilen "Kimlik ve Kültür Metaforları Anketi” kullanılmıştır. Verilerin analizinde betimsel istatistiklerin yanı sıra içerik analizleri de yapılmıştır. Çalışma sonunda öğretmen adaylarının kültür kavramına yönelik olarak en çok "gelişen bir varlık" kategorisinde metafor ürettikleri görülmüştür. Kimlik kavramında ise oluşturulan metaforlar kimliğin milli olarak algılanmadığını göstermiștir.

Anahtar kelimeler; kültür, kimlik, metafor

\begin{abstract}
Identity is defined as "the totality of the minds that people establish through communication and language concerning who they are and the social world". The culture which many different definitions are made is "a structure containing the institutions that will provide harmony and solidarity to maintain the life of a community, communicate between persons; containing the values, rules and beliefs to be applied when making sense of life". These concepts are among the main factors that contribute to the sense of belonging to the individual in social life. As a matter of fact, in this study, it has been tried to determine the perceptions of the university students about the concepts of "identity and culture" and the sources which are influential in these perceptions through the metaphors that they developed towards the related concepts. Metaphors enable concrete concepts and visualization of abstract concepts in their minds, thereby increasing the motivation to learn by allowing the learned knowledge to remain in the mind longer and easier to remember. In this context, the metaphors that are expected to be developed on the abstract concept of "culture and identity" will reveal the perception of these concepts and the possible causes of this occurrence. The sample of the research consists of 408 students studying in I., II., III., and IV. classes in the department of Social Sciences Teaching in Atatürk University Kazim Karabekir Education Faculty in 2014 year. The "Identity and Culture Metaphors Questionnaire" developed by the researcher was used to collect the data. Descriptive statistics as well as content analysis have been made in the analyze of the data.In end the study, it was seen that teacher candidates produces metaphors in the category of "developing asset" most fort he concept of cuture. The metaphors created in the concept if identity have shown that the identity is not perceived as national.
\end{abstract}

Keywords; culture, identity, metaphor.

\footnotetext{
* Sorumlu yazar (Corresponding author)
} 


\section{GİRIS}

Bir toplumun tarihsel süreç içinde ürettiği ve kuşaktan kuşağa aktardığı her türlü maddi ve manevi özelliklerin bütününe kültür denir. Kültür, bir toplumun kimliğini oluşturur, onu diğer toplumlardan farklı kılar. Kültür, toplumun yaşayış ve düşünüş tarzıdır.

Bilim adamları kültür kavramını tüm toplumsal grupları düzenleyen organik kuralları, düşünsel eğilimleri ve sanatları, gelenek, görenek, inanç ve adetleri, aletleri ve tüketim maddelerini, ahlaksal kuralları, insanların gerçekleştirdiği yetenek ve alışkanlıkları içine alan bütünsel bir olgu olarak tanımlamaktadırlar.

Kültürün Özellikleri:

Kültür görelidir. Yani her toplumun kendine özgü kültürü vardır.

Kültür tarihseldir. Geçmişten günümüze süregelmektedir.

Kültür insan eseridir. İnsanlar hem kültürü oluştururlar hem de kültürden etkilenirler.

Kültür durağan değildir. Zaman içinde değişir. Maddi öğeler daha hızlı değişir. Ayrıca her toplumda kültürel değişim hızı birbirinden farklıdır

Latince "idem" kökünden gelen "kimlik (identity)" kavramının uzun bir tarihi olduğu halde, 20. yüzyıla kadar popüler bir kavram olarak kullanıldığı söylenemez (Marshall, 2009:405). İçinde bulunulan 21. yüzyılda ise kimlik, çağdaş hayatın tartışmalı yönlerini aydınlatmaya, kavramaya ve incelemeye yarayan bir prizma haline gelmiştir (Bauman, 2011). Toplumsal analize konu olan yerleşik meseleler "kimlik" ekseni etrafinda dönmekte olan söyleme uymak için farklı biçimde yeniden ele alınmakta ve düzenlenmektedir (Bauman, 2011). Kimlik toplumsal anlamda, simgesel etkileşimciliğin tanımıyla insanların kim olduklarıyla ve toplumsal dünyayla ilgili olarak iletişim ve dil aracılığıyla kurdukları düşünceler bütünüdür (Tüba, 2011:720). Başka bir tanıma göre ise, kimlik; kişinin toplum içindeki rolünü ve konumunu açık biçimde anlamasına olanak veren, başkalarınca tanınması ile kendini tanımlaması arasındaki ilişki sürecinde belirginleşen, toplumsal ve kültürel ilişkinliği belirleyen tutumun kaynağı olan kavramdır (Tüba, 2011:720).

21. yüzyıl; ortaya çıkan siyasi, ekonomik toplumsal, bilimsel ve teknolojik gelişmelerin etkisiyle bireylerin yaşam biçimlerinin köklü biçimde değişime uğradığı bir zaman dilimi olmayı sürdürmektedir. Kimliklerin sabit bir durum olmadığı göz önüne alındığında, yaşanan değişimler kimlik yapılarını da değiştirmektedir. Kimliklerin belirlenmesinde etkin olan değerlerin zaman içinde önemini kaybetmekte, onların yerini farklı değerler doldurmaktadır. Ya da boşalan değerlerin yeri dolmadığı takdirde kimlik bunalımları, kimlik kargaşaları gibi durumlar ortaya çıkmaktadır ki, bunlar içinde bulunulan 21. yüzyıla özgü kavramlardır. Ben kimim? Hangi kültüre aitim? gibi sorulara verilen cevaplar nesilden nesile değişmeye başlamıştır.

Bireylerin kimlik ve kültür algılarının bilinmesi toplumsal yapıların daha iyi anlaşılmasını olanaklı hale getirecektir. Kimlik ve kültür algısının belirlenmesinde bireyler tarafından geliştirilen metaforlar ayrı bir öneme sahiptir. Metafor kelime olarak, Grekçe "Metapherein" kelimesinden türetilmiş olup, "Meta" (değiştirmek) ve "pherein" (taşımak) sözcüklerinin birleşmesiyle oluşturulmuştur (Levine, 2005:172). Metafor günümüzde, daha ziyade söylemi süslemeye yönelik bir söz sanatı olarak bilinmekle birlikte, Metafor kullanımı genel olarak dünyayı kavrayışımıza yardım eden bir düşünme ve görme biçimi anlamına gelmektedir. Bilimsel araştırmalar göstermiştirki metaforik düşünme biçimi, dil ve bilim üzerinde olduğu kadar, insanın günlük yaşamında kendini ifade edişi üzerinde de biçimlendirici bir etki yapmaktadır (Morgan, 1998:14).

Metaforlar öğrencilerin özellikle zor kavram ve terimleri daha net bir şekilde anlamalarına yardımcı olarak soyut kavramların zihinde somutlaştırılması ve görselleştirilmesini sağlamakta ve böylece öğrenilen bilgilerin akılda daha uzun süre kalmasını ve daha kolay hatırlanmasını sağlayarak öğrenme motivasyonunu artırmaktadır. Eğitim yönetiminde metaforlar müfredat geliştirme ve planlamada; öğretim alanında öğrenmeyi teşvik etme ve yaratıcı düşünceyi geliştirmede, öğretmen eğitiminde ise metaforlar, öğretim uygulamalarını yönlendirmede ve öğretmenlerin modern eğitim anlayışlarındaki yerlerini belirlemede bir araç konumundadır (Arslan ve Bayrakçı, 2006).

Son yıllarda, dünyada olduğu gibi ülkemizde de metaforların belli başlı sosyal ortamlardaki faaliyetlere nasıl rehber olduğu, inançları, tutumları ve değerleri nasıl şekillendirdiği, örgütsel süreçleri nasıl gösterdiği ve örgütsel yaşamın oluşturulmasında nasıl vurgulandığına yönelik olarak ilginin arttığı görülmektedir (Çelikten, 2006:270). Bu ilgi hayatın her alanında olduğu gibi eğitim ve öğretim alanında da kendisini göstermektedir. Ülkemizdeki eğitim ve öğretim alanında yapılan bilimsel çalışmalarda metafor üzerine öğrencilerin okulu algılamaları (Aydoğdu, 2008; Balcı, 1999), öğretmen adaylarının öğretmen kavramına bakış açıları (Cerit, 2008; Ocak ve Gündüz, 2006; Pektaş ve Kıldan, 2009; Saban, 2005), öğretmen eğitim programları (Oğuz, 2005), düşünme ve öğrenme yaklaşımı (Arslan ve Bayrakçı, 2006) ve coğrafya kavramı (Öztürk, 2007) gibi çok farklı konularda araştırmalar yapılmıştır. Yine Koçak, Aydın \& Subaşı (2016)'nın üstün yetenekli çocuklarla yaptıkları metafor çalışmasında "bilim insanı”na yönelik metaforlar üretilmesi istenmiştir. Metafor çalışmalarının fen bilimleri ve sosyal bilimlerin her alanında çeşitli kavramlara yönelik algıları belirlemek için kullanıldığı yapılan çalışmalardan da anlaşılmaktadır. Bu bağlamda bu araştırmada da kültür ve kimlik kavramları ele alınmış ve çalışmanın amacı yüksek öğretim öğrencilerinin "kültür” ve "kimlik" kavramı hakkındaki algılarını geliştirdikleri metaforlar aracılığıyla ortaya çıkarmaktır. Bu amaç doğrultusunda araştırmanın alt problemleri aşağıdaki gibi belirlenmiştir. 
1.Kültür kavramı hakkında geliştirilen metaforlar nelerdir?

2. Kültür kavramı hakkındaki geliştirilen metaforların ortak özellikleri nelerdir?

3. Kültür kavramına yönelik geliştirilen metaforların, çeşitli değişkenler açısından dağılımı nasıldır?

4. Kimlik kavramı hakkında geliştirilen metaforlar nelerdir?

5. Kimlik kavramı hakkındaki geliştirilen metaforların ortak özellikleri nelerdir?

6. Kimlik kavramına yönelik geliştirilen metaforların, çeşitli değişkenler açısından dağılımı nasıldır?

\section{YÖNTEM}

Olgular yaşadığımız dünyada olaylar, deneyimler, algılar, yönelimler, kavramlar ve durumlar gibi çeşitli biçimlerde karşımıza çıkabilmektedir. Ancak bu kavramların ne olduğu kadar insanlar tarafından nasıl algılandığı ve anlamlandırıldığı da çok önemlidir. Nitekim insanların kavramlara, durumlara yükledikleri anlamlar gerçeğe yakın olduğu kadar yanlış ve eksik de olabilmektedir. Bu nedenle tümüyle yabancı olmadığımız, ancak tam anlamını da kavrayamadığımız olguları araştırmayı amaçlayan çalışmalar için olgubilim (fenomenoloji) uygun bir araştırma zemini oluşturmaktadır (Yıldırım ve Şimşek, 2008: 72). Bu çalışmada öğretmen adaylarının kültür ve kimlik kavramları hakkında derinlemesine ve ayrıntılı bir anlayışa sahip olup olmadıklarını belirleyerek ilgili kavramlara odaklanmak temel amacımız olduğundan, çalışmada olgubilim deseni kullanılmıştır.

\section{Çalışma Grubu}

Araştırmanın örneklemini, 2013-2014 eğitim-öğretim yılında, Atatürk Üniversitesi Kazım Karabekir Eğitim Fakültesi Sosyal Bilgiler Öğretmenliği programı I, II, III ve IV. sınıfta öğrenim gören 138'si kız, 270’i erkek olmak üzere toplam 408 öğrenci oluşturmaktadır. Çalışma grubu oluşturulurken amaçlı örnekleme kullanılmıştır. Daha çok nitel çalışmalarda tercih edilen bu örnekleme türü kullanılmıştır. Sosyal bilgiler dersi içerdiği konular itibariyle öğrencilere kültürü tanıtan ve anlatan ve onlara bir kimlik kazanmaları için yol gösterici bir niteliğe sahip olan bir ortaokul dersidir. Bu nedenle bu dersi öğretmeye namzet olan öğretmen adayları üzerinde bu çalışma gerçekleştirilmiştir. Araştırma yapılırken amaç elde edilen verileri evrene genellemek değil, üzerinde araştırma yapılan durumu derinlemesine betimlemektir (Ekiz, 2009).

\section{Verilerin Toplanması}

Verilerin toplanması için, 2013-2014 eğitim-öğretim yllında Atatürk Üniversitesi Kazım Karabekir Eğitim Fakültesi Sosyal Bilgiler Öğretmenliği bölümünde eğitim gören I., II., III. ve IV. sınıf öğrencilerinden "Kültür...........gibidir; çünkü, ........ . "Kimlik........ gibidir; çünkü ..........." cümlelerini tamamlamaları istenmiştir. Böylece kültür ve kimlik kavramlarına ilişkin öğrencilerin sahip oldukları metaforlar tespit edilmiştir. Kültür ve kimlik kavramlarından yola çıkılarak öğrencilere herhangi bir yönlendirme yapılmadan 1 ders saati içerisinde metafor oluşturmaları istenmiştir. Böylece öğrencilerin herhangi bir uzman kişinin ve arkadaşlarının etkisinde kalmadan özgün birer metafor oluşturmaları sağlanmıştır.

\section{Verilerin Analiz Edilmesi ve Yorumlanması}

Araştırmada toplam 408 öğrenciden metafor oluş̧urmaları istenmiştir. Dağıtılan formları eksik dolduran veya metafor yazıp benzetme açıklamasını yapmayan öğrenciler ile oluşturduğu metaforlarda birden çok tasvirin yapıldığı metaforlar değerlendirme dışında bırakılmıştır. Bu eleme sonucunda kültür kavramı için 303, kimlik kavramı için ise 259 geçerli metafor üretilmiştir. Daha sonra araştırma kapsamına dahil edilen metaforlar alfabetik sıraya göre listelenmiş ve her bir metaforu temsil eden öğrenci sayısı ve yüzdesi hesaplanmıştır.

408 kişinin katılımıyla hazırlanan bu çalışmada öğretmen adaylarının 55'i kültür (geçerli metafor sayısı 303), 149'u ise kimlik metaforuna (geçerli metafor sayısı 259) cevap vermemiştir. Kayıp veri olarak kimlik metaforunun sayısının oldukça yüksek olması, katılımcıların kimlik kavramı hakkında net bir bilgi sahibi olmadıklarını göstermektedir. Nitekim kimlik metaforunu yanıtlamayan katılımcıların bazıları bu metaforun ne demek olduğunu bilmediklerini ifade etmişlerdir.

Geçerli metaforlar belirlendikten sonra her iki kavram için de içerik analizi yapılarak metaforlar belirlenen kategoriler altında sınıflandırılmıştır. Kategoriler belirlenirken kodlayıcı güvenirliği çalışması kapsamında, araştırmacılar tarafından ayrı ayrı yapılan kodlamalar karşılaştırılarak aradaki uyum test edilmiştir. Miles ve Huberman'n (1994: 64) formülü (güvenirlik=görüş birliği/ görüş birliği+görüş ayrıllğı x 100) kullanılarak yapılan hesaplamalarda kodlayıcılar arasındaki uyuşma oranının 0.89 olduğu tespit edilmiştir.

Yine yapılan bu çalışmada ilgili metaforlara verilen cevaplarla "cinsiyet, yaş, sınıf, yaşanılan bölge, anne ve baba eğitim durumu, mesleği ve ailenin eğitim durumu" değişkenleri arasında bir ilişki olup olmadığına da SPSS programıyla bakılmış, ancak bu değişkenlerle "kültür ve kimlik" metaforlarına verdikleri cevaplar arasında bir bağlantı olmadığı da görülmüştür. Değiş̧enler ile metaforlar arasında bir bağlantı bulunamamasına rağmen, cinsiyet, yaşanılan bölge ve sınıf değişkenleri için elde edilen veriler çalışmada sunulmuştur.

Oluşturulan bu metaforlar alfabetik sıraya ve bölümlerine göre listelenerek her bir metaforu temsil eden öğrenci sayısı ve yüzdesi tablo haline getirilerek gösterilmiştir. Araştırmada verilerin çözümlenmesi için SPSS programı aracılığıyla betimsel analiz ve kategorilerin oluşturulması için ise içerik analizi yapılmıştır. 


\section{BULGULAR VE YORUM}

408 öğrencinin katılımıyla hazırlanan bu çalışmada öğretmen adaylarının 55'i kültür, 149'u ise kimlik kavramlarına cevap vermemiştir. Kayıp veri olarak kimlik kavramında sayının oldukça yüksek olması, katılımcıların kimlik kavramı hakkında net bir bilgi sahibi olmadıklarını göstermektedir. Nitekim kimlik kavramına bir metafor üretmeyen katılımcıların bazıları bu kavramın ne demek olduğunu bilmediklerini ifade etmişlerdir. Ayrıca öğrencilerin kimlik kavramına yönelik metafor geliştirememedeki sebepleri arasında ya bu kavramın hassasiyeti ya da öğrencilerin kavram hakkında fikir sahibi olmamaları önemli bir ihtimaldir.

Öğretmen adaylarının kültür kavramına yönelik olarak ürettikleri metaforlar ve bu metaforların çeşitli değişkenler açısından yapılandırılmış tabloları Tablo 1,2,3,4,5'te verilmiştir. Tablo 1'de "kültür" kavramı için belirlenmiş olan metaforlar yer almaktadır.

Tablo 1.

Kültür Kavramı için üretilen metaforlar

\begin{tabular}{|c|c|c|c|c|c|}
\hline Metafor & $f$ & Metafor & $f$ & Metafor & $f$ \\
\hline Ăgaç & 8 & Elbise & 1 & Mantar & 1 \\
\hline Ahlaki toplum & 1 & Elmas & 2 & Merdiven & 1 \\
\hline Aile & 7 & Emek & 1 & Meyve & 2 \\
\hline Aitlik & 1 & Ev & 3 & Milletin Aslı & 1 \\
\hline Akarsu & 3 & Evin temeli & 1 & Miras & 9 \\
\hline Alış-veriş & 1 & Farklilik & 1 & Moda & 1 \\
\hline Ana sütü & 1 & Geçmiş & 2 & Mozaik & 1 \\
\hline Anne-baba & 5 & Geçmiş, Gelecek & 2 & Mücadele & 1 \\
\hline Araba & 1 & Gelenek Görenek & 5 & Namus & 1 \\
\hline Aşure & 1 & Geniş Yapraklı Ağaç & 1 & Nefes & 2 \\
\hline Ayırt Edici Özellik & 1 & Giyim-Kuşam & 2 & Okyanus & 3 \\
\hline Ayna & 5 & Gökkuşağ1 & 4 & Olmayan & 1 \\
\hline Babaanne-Dede & 1 & Güçlerin Gıdası & 1 & Orman & 2 \\
\hline Bavul & 1 & Hamur & 2 & Öğretmen & 1 \\
\hline Ben & 1 & Hard disk & 1 & Ölümsüzlük & 1 \\
\hline Benlik & 3 & Hava & 2 & Örümcek Ağ1 & 1 \\
\hline Bilgi & 1 & Hayat & 11 & Para & 3 \\
\hline Bilgi Birikimi & 1 & Hayatımızı Şekillendiren Kural & 1 & Paylaşma & 1 \\
\hline Bina & 1 & Hazine & 2 & Renkler & 2 \\
\hline Birikim & 1 & Her şey & 8 & Roman & 1 \\
\hline Bitki Tohumu & 1 & Iş1k & 1 & Sanat & 1 \\
\hline Bizi Biz Yapan Değerler & 1 & İç Deniz & 1 & Sarılmak & 1 \\
\hline Boş Bir Fıçı & 1 & İnsan & 14 & Sarmaşık Çiçeği & 2 \\
\hline Buğday & 1 & İnsan Beyni & 1 & Saygınlık & 1 \\
\hline Bulaşıcı Hastalık & 2 & İnsanın Benimsediği Değerler & 1 & Seyyah & 1 \\
\hline Bütünleştirici Bir Olgu & 1 & İnsanın Değerleri & 2 & Sinav & 2 \\
\hline Canlı Bir Organizma & 1 & İnsanın Hayat Damarı & 1 & Sonsuzluk & 1 \\
\hline Canlı Varlık & 1 & İnsanın Kendisi & 2 & $\mathrm{Su}$ & 11 \\
\hline Coğrafya & 2 & İnsanın Kişiliği & 1 & Süreç & 1 \\
\hline Çam ağacı & 1 & İnsanın Yaptığg Her Şey & 1 & Şehir & 1 \\
\hline Çevreden Edindiklerimiz & 1 & İnsanın Yarattığı Her Şey & 2 & Tarih & 4 \\
\hline Çiçek & 3 & İnsanlık Birikimi & 1 & Tarz & 2 \\
\hline Çocuk & 1 & $\dot{\mathrm{I} p}$ & 1 & Toplum & 3 \\
\hline Davranış & 2 & Kalıp & 1 & Toplumun Kalbi & 1 \\
\hline Değerler & 3 & Kalp & 2 & Toplumun Varoluşu & 1 \\
\hline Değişken & 2 & Karakutu & 1 & Toprak & 1 \\
\hline Deniz-Okyanus & 3 & Kaybedilen Değer & 2 & Türk Kahvesi & 1 \\
\hline Devlet & 2 & Kendini Bilmek & 1 & Türlü (yemek) & 2 \\
\hline Dil & 2 & Kiyafet & 2 & Ülkenin Marş1 & 1 \\
\hline Dil, Gelenek, Görenek & 1 & K1z Kardeş & 1 & Ülkenin Zenginliği & 1 \\
\hline Donanım & 1 & Kimlik & 6 & Varlık & 1 \\
\hline Düğün & 1 & Kişinin Kimliği & 1 & Vatan & 1 \\
\hline Dünya & 4 & Kitap & 1 & Yapı Taş1 & 1 \\
\hline Ekin ekmek & 3 & Kuş & 2 & Yaşam & 18 \\
\hline
\end{tabular}




\begin{tabular}{llllll}
\hline Ekmek & 2 & Lezzet & 1 & Yaşam Biçimi & 7 \\
\hline Metafor & $f$ & Metafor & $f$ & Metafor & $f$ \\
\hline Ekmek-su & 1 & Maddi Manevi Değer & 2 & Yaşanılan Yer & 2 \\
\hline & Makine & 1 & Yemek & 4 \\
\hline & & & & Toplam & $\mathbf{1 4 0}$ \\
\hline
\end{tabular}

Tablo 1'de görüldüğü gibi kültür kavramı için toplam 140 farklı metafor üretilmiştir. Bu metaforlar arasında frekansı en fazla olan "yaşam" (18) metaforu olmuştur. Bu metaforu 14 frekans ile "insan" metaforu takip etmiştir. Bu metaforlar öğretmen adaylarının metaforlara yönelik yaptıkları açıklamalar dikkate alınarak araştırmacılar tarafından kategorilere ayrılmıştır. Kültür kavramı için belirlenen kategoriler Tablo 2'de görülmektedir.

Tablo 2.

Kültür metaforlarl için belirlenen kategoriler ve bu kategorilerin ifade edilme slklı̆̆

\begin{tabular}{l|l|l}
\hline Kültür Metaforu Kategorileri & $\mathbf{f}$ & $\mathbf{\%}$ \\
\hline Aidiyet & 1 & 0,3 \\
\hline Ayırt Edici & 31 & 10,2 \\
\hline Bütünleştirici & 2 & 0.6 \\
\hline Değer & 27 & 8,9 \\
\hline Etkileşim & 24 & 7,9 \\
\hline Farklılıkları barındıran & 39 & 12,8 \\
\hline Gelişen Bir Varlık & 60 & 19,8 \\
\hline Kapsayıcı & 27 & 8,9 \\
\hline Ortak Bir Geçmiş & 38 & 12,5 \\
\hline Tutucu & 2 & 0,6 \\
\hline Vazgeçilmez & 27 & 8,9 \\
\hline Yansıtıcı & 22 & 7,2 \\
\hline Yanılg1 & 3 & 0,9 \\
\hline Toplam & 303 & 100 \\
\hline
\end{tabular}

Tablo 2'de görüleceği gibi kültür kavramı için üretilen metaforlarda en yüksek kategori olarak 60 metaforla $(\% 19,2)$ "gelişen bir varlık" kategorisini görmek mümkündür. Bu kategorinin ardından 39 metaforla $(\% 12,8)$ "farklılık" kategorisi, 38 metaforla (\%12,5) "ortak bir geçmiş" kategorileri yer almaktadır. İlk üç sırayı takiben sırayla "ayırt edici" (31/\%10,2), değer (27/\%8,9), kapsayıcı $(27 / \% 8,9)$, vazgeçilmez $(27 / \% 8,9)$, etkileşim $(24 / \% 7,9)$, yansitıcı $(22 / \% 7,2)$ kategorileri sıralamada yer almaktadır. Kültür kavramı metaforları arasında en düşük orana sahip olan kategorileri ise tutucu $(2 / \% 0,6)$, bütünleştirici $(2 / \% 0,6)$ ve son sirada tek bir metaforla aidiyet $(\% 0,3)$ metaforu bulunmaktadır. Bu kavrama yönelik olarak yanılgı içeren metaforların sayısı ise $3(\% 0,9)$ 'tür.

Kültür kavramı için üretilen metaforları kategorilere ayırmamızı sağlayan açıklamalar aynı ölçme aracı vasıtasıyla alınmıştır. Örneğin;

Gelişen bir varlık:

- “Ağaç gibidir, zamanla büyür gelişir" (Ö6).

- "İnsan gibidir, doğar, büyür ve ölür" (Ö11).

- "Canlı bir organizma gibidir, gelişir ve değişiri" (Ö162).

- "İnsan beyni gibidir, gelişir” (Ö 142).

Farklılıkları barındırır:

- "Dügüü gibidir, farklı hal ve hareketler, giyinişler vardır”(Ö124).

- "Bavul gibidir, içine çok şey sı̆̆dırırsın" (Ö43).

- "Türlü yemek; karışıktır, içinde her şey vardır” (Ö348).

Ortak bir geçmiş:

- Miras gibidir, geçmişe dayanır" (Ö14).

- "Sarılmak gibidir, toplumun ortak duygu ve düşünceleridir” (Ö102).

Etkileşim:

- "Bulaşıcı hastalık gibidir, yayılmacıdır" (Ö74).

- "Dil gibidir, milleti temsil eder"(Ö26).

Ayırt edici unsur:

- "Elbise gibidir, millete özgüdür, değişkenlik gösterir”(Ö76).

Kapsayıcı: 
- "Hard disk gibidir, içinde her türlü kaynak ve veri bulunur”(Ö139).

Vazgeçilemez:

- "Namus gibidir, kaybedersek benliğimizi de kaybederiz"(Ö18).

- “Ekmek/su gibidir, yaşamsal ihtiyaçlar kadar gereklidir”(Ö281).

\section{Yanılgılar:}

- "Olmayan bir şey gibidir, evrensel değildir".

- "Sarmaşı gibidir, çok çeşitli kavramları vardır".

- "Su gibidir, değişim ve gelişimdir".

Yukarıda ifade edilen metafor açıklamalarından da anlaşılacağı gibi açıklamalar üretilen metaforun en temel özelliği ile açıklanmıştır. Bir bavulun her şeyi içine alabilmesi, namusun bir insan için kaybedilmemesi gereken önemli bir unsur olması gibi. Yanılgı olarak ayrılan metaforlarda ise ya yapılan açıklama tam olarak anlaşılamamış ya da metaforla açıklama birbiriyle uyuyşmamaktadır.

Tablo 3 .

Cinsiyet değişskenine göre kültür metaforu kategorilerinin dă̆glımı

\begin{tabular}{llll}
\hline \multirow{2}{*}{ Kategori } & \multicolumn{3}{c}{ Cinsiyet } \\
\cline { 2 - 4 } & Erkek & Kadın & Toplam \\
\hline Aidiyet & - & 1 & 1 \\
\hline Ayırt Edici & 13 & 18 & 31 \\
\hline Bütünleştirici & 1 & 1 & 2 \\
\hline Değer & 6 & 21 & 27 \\
\hline Etkileşim & 14 & 10 & 24 \\
\hline Farklılık & 22 & 17 & 39 \\
\hline Gelişen Bir Varlık & 36 & 24 & 60 \\
\hline Kapsayıcı & 19 & 8 & 27 \\
\hline Ortak Bir Geçmiş & 19 & 19 & 38 \\
\hline Tutucu & 1 & 1 & 2 \\
\hline Vazgeçilmez & 14 & 13 & 27 \\
\hline Yansıtıc1 & 11 & 11 & 22 \\
\hline Yanılg1 & 1 & 2 & 3 \\
\hline Toplam & 157 & 146 & 303 \\
\hline
\end{tabular}

Kültür kavramına ilişkin üretilen metaforlar çalışmada çeşitli değişkenler açısından da incelenmiştir. Tablo 3'te kültür kavramı için kadın ve erkek öğretmen adaylarının ürettiği metaforlar yer almaktadır. Bu değişkene göre hem erkek (36) hem kadın (24) öğrencilerde en çok seçilen kategori "gelişen bir varlık" kategorisi olmuştur. "Ortak bir geçmiş" (19) ve "yansıtıcı" (11) kategorileri için her iki guruptan da eşit sayıda metafor üretilmiştir. Üretilen metaforlar ile kategoriler arasında cinsiyet açısından en büyük farklılığın olduğu kategori ise değer kategorisi olmuştur. Bu kategoride erkek öğrenciler 6 metafor üretmelerine rağmen, kız öğrenciler 21 metafor üretmişlerdir.

Tablo 4'te bölgeler bazında kültür metaforuna yönelik olușturulan kategorilerin dağılımı görülmektedir. Çalışmaya katılan öğrencilerin büyük bir çoğunluğu Doğu Anadolu Bölgesi'nden oldukları için her kategoride bu bölgede yaşayan öğrencilerin oluşturduğu metaforlar yüksek sayıda görünmektedir. Ancak sayı az dahi olsa Güneydoğu Anadolu Bölgesi'nde yaşayan öğrencilerin \%22,7 (10)'u kültürü "gelişen bir varlık" olarak değerlendirmişlerdir. Yine aynı bölgede yaşayan öğrencilerin \%15,9 (7) ile oluşturdukları ikinci kategori ise "ayırt edici" kategorisi olmuştur. Karadeniz Bölgesinde yaşayan öğrencilerin oluşturdukları metaforlarda ise birinci sırayı \%25 (6) "ortak bir geçmiş" kategorisi almışken, ikinci sırayı \%20,8 (5) ile "vazgeçilmez" kategorisi almıştır. Akdeniz Bölgesi'nde yaşayan öğrencilerin en yüksek sayı ile katıldıkları kategori Güneydoğu Anadolu Bölgesi’nde yaşayan öğrencilerde olduğu gibi \%35 (7) "gelişen bir varlık" ategorisi olmuştur. Diğer bölgelerde kategoriler arasındaki dağılım daha homojen şekilde gerçekleşmiştir. 
Tablo 4.

Yaşanılan bölge değişkenine göre kültür metaforu kategorilerinin dağılımı

\begin{tabular}{|c|c|c|c|c|c|c|c|c|}
\hline \multirow[t]{2}{*}{ Kategori } & \multicolumn{8}{|c|}{ Yaşanılan Bölge } \\
\hline & 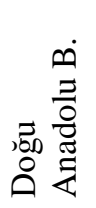 & 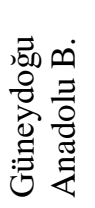 & 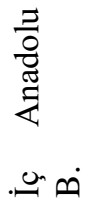 & 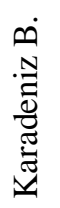 & $\begin{array}{l}\dot{0} \\
\cdot \stackrel{N}{0} \\
\frac{0}{0} \\
\frac{\theta}{2}\end{array}$ & $\begin{array}{l}\dot{\varphi} \\
\stackrel{\Delta}{\Phi} \\
\dot{I}\end{array}$ & 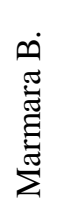 & $\frac{\Xi}{\frac{\pi}{0}}$ \\
\hline Aidiyet & 1 & 0 & 0 & 0 & 0 & 0 & 0 & 1 \\
\hline Ay1rt Edici & 18 & 7 & 1 & 0 & 2 & 2 & 1 & 31 \\
\hline Bütünleştirici & 1 & 1 & 0 & 0 & 0 & 0 & 0 & 2 \\
\hline Değer & 18 & 5 & 1 & 2 & 0 & 1 & 0 & 27 \\
\hline Etkileşim & 14 & 2 & 3 & 1 & 1 & 1 & 2 & 24 \\
\hline Farklılık & 24 & 3 & 1 & 2 & 3 & 2 & 4 & 39 \\
\hline Gelişen Bir Varlık & 37 & 10 & 2 & 4 & 7 & 0 & 0 & 60 \\
\hline Kapsayıcı & 16 & 5 & 1 & 1 & 4 & 0 & 0 & 27 \\
\hline Ortak Bir Geçmiş & 25 & 5 & 0 & 6 & 1 & 1 & 0 & 38 \\
\hline Tutucu & 2 & 0 & 0 & 0 & 0 & 0 & 0 & 2 \\
\hline Vazgeçilmez & 16 & 4 & 0 & 5 & 0 & 0 & 2 & 27 \\
\hline Yansitici & 13 & 2 & 0 & 3 & 2 & 0 & 2 & 22 \\
\hline Yanılg1 & 3 & 0 & 0 & 0 & 0 & 0 & 0 & 3 \\
\hline Toplam & 188 & 44 & 9 & 24 & 20 & 7 & 11 & 303 \\
\hline
\end{tabular}

Çalışmada belirlenen bir diğer değişken ise sınıftır. Tablo 5'te bu değişken ile ilgili veriler sunulmuştur.

Tablo 5.

Sınıf değişkenine göre kültür metaforu kategorilerinin dă̆ılımı

\begin{tabular}{|c|c|c|c|c|c|}
\hline Kategori & $\begin{array}{l}\stackrel{4}{\Xi} \\
\stackrel{\Xi}{\circ} \\
-\end{array}$ & $\begin{array}{l}\text { 崩 } \\
\text { ن }\end{array}$ & $\begin{array}{l}\stackrel{4}{\Xi} \\
\dot{\infty} \\
\dot{n}\end{array}$ & $\begin{array}{l}\text { 崩 } \\
\dot{+}\end{array}$ & $\frac{\Xi}{\frac{\pi}{0}}$ \\
\hline Aidiyet & 0 & 0 & 0 & 1 & 1 \\
\hline Ayırt Edici & 4 & 7 & 16 & 4 & 31 \\
\hline Bütünleştirici & 0 & 0 & 2 & 0 & 2 \\
\hline Değer & 14 & 4 & 8 & 1 & 27 \\
\hline Etkileşim & 8 & 5 & 7 & 4 & 24 \\
\hline Farklılik & 12 & 4 & 15 & 8 & 39 \\
\hline Gelişen Bir Varlık & 22 & 13 & 16 & 9 & 60 \\
\hline Kapsayıcı & 7 & 4 & 8 & 8 & 27 \\
\hline Ortak Bir Geçmiş & 13 & 8 & 12 & 5 & 38 \\
\hline Tutucu & 0 & 1 & 1 & 0 & 2 \\
\hline Vazgeçilmez & 9 & 3 & 10 & 5 & 27 \\
\hline Yansitici & 5 & 5 & 12 & 0 & 22 \\
\hline Yanılg1 & 0 & 0 & 3 & 0 & 3 \\
\hline Toplam & 94 & 54 & 110 & 45 & 303 \\
\hline
\end{tabular}

Tablo 5 incelendiğinde "gelişen bir varlık" kategorisinin 1., 2. ve 4. sinıflarda birinci sirayı aldığı görülmektedir. 3. sınıflarda birinci sırayı 16 metaforla "gelişen bir varlık" ve "ayırt edici" kategorileri paylaşmaktadır. "Değer" kategorisi 1. sınıflarda 14 metaforla ikinci sırada yer alırken, 4. sınıflarda bu kategoriye yönelik metafor geliştiren öğrenci sayısı 1'dir. "Ortak bir geçmiş" kategorisine yönelik 1. (13) ve 3. (12) sinıflarda oldukça yakın sayıda metafor üretilmişken, 2. (8) ve 4. (5) sınıflarda bu kategori için geliştirilen metafor sayısı daha azdır. "Ayırt edici" (16) ve "yansıtıcı" (12) kategorileri için de en fazla metafor 3. sınıfta üretilmiştir.

Sosyal Bilgiler öğretmen adaylarına yapılan bu çalışmada metafor üretilmesi istenilen bir diğer kavram “kimlik”tir. Öğretmen adayları bu kavram için de çok sayıda metafor üretmişlerdir. Ancak kültür kavramına nazaran bu kavrama yönelik oluşturulan metafor sayısı daha azdır. Kimlik kavramı için oluşturulan metafor listesi Tablo 6'da gösterildiği gibidir. 
Tablo 6.

Kimlik kavramı için üretilen metaforlar

\begin{tabular}{|c|c|c|c|c|c|}
\hline Metafor & f & Metafor & $\mathbf{f}$ & Metafor & $\mathbf{f}$ \\
\hline Adres & 1 & Geçmiş & 2 & Okul & 1 \\
\hline Ağacın Kökü & 1 & Gelecek Nesil & 1 & Olma & 1 \\
\hline Ağaç & 3 & Gemi & 1 & Organizma & 1 \\
\hline Ağaç türü & 1 & Gömlek & 1 & Ödül & 1 \\
\hline Ahlak & 1 & Güneş & 1 & Öz benlik & 1 \\
\hline Aidiyet & 1 & Hafiza & 1 & Özgürlük & 2 \\
\hline Aile & 4 & Hava & 1 & Parmak İzi & 1 \\
\hline Aldatma & 1 & Hayat & 5 & Portakal & 1 \\
\hline Anahtar & 1 & Hürriyet & 1 & Prensip & 2 \\
\hline Anayasa & 1 & Irk-soy & 2 & Renk & 1 \\
\hline Arayış & 1 & İç Dünya & 1 & Resim & 3 \\
\hline Ay & 1 & İnsanın Yansıması & 2 & Rol & 2 \\
\hline Ayna & 24 & İnsanın Yurdu & 1 & Ruh & 1 \\
\hline Bağımsızlık & 3 & İnsanlik & 1 & Saygınlık & 2 \\
\hline Barkod & 1 & İsim & 3 & Sima & 1 \\
\hline Belge & 1 & Kafa & 1 & Statü & 3 \\
\hline Ben & 4 & Kafa Kağıdı & 1 & $\mathrm{Su}$ & 4 \\
\hline Benlik & 7 & Kalem & 1 & Şahsiyet & 1 \\
\hline Beyaz & 2 & Karakter & 4 & Şifre & 1 \\
\hline Bilgisayar & 1 & Kazanımlar & 2 & Tablo & 1 \\
\hline Birey & 1 & Kendimiz & 1 & Tahta & 1 \\
\hline $\mathrm{Biz}$ & 3 & Kendimizi Bulma & 1 & İçi Görünmeyen kutu & 1 \\
\hline Boş Havuzu Doldurmak & 1 & Kendini Aşma & 1 & İnsan & 9 \\
\hline Boş Kağıt & 1 & Kendini Gerçekleştirme & 1 & İnsanın Kişiliği & 1 \\
\hline Boşluk & 1 & Kendini Kabullenme & 1 & İnsanın Kendisi & 1 \\
\hline Çamur & 1 & Kendini Tanıtma & 1 & İnsanın Özü & 1 \\
\hline Davranış & 1 & Kim Olduğumuz & 1 & İnsanın Resmi & 1 \\
\hline Değer & 1 & Kimlik & 2 & Tanınmaz & 1 \\
\hline Değer Kazandırmak & 1 & Kişi & 4 & Tanitım & 2 \\
\hline Değişik Hayatlar & 1 & Kişilik & 23 & Tapu & 2 \\
\hline Deniz & 1 & Kişisel Bilgi & 2 & Tarihi Eser & 1 \\
\hline D1ş Görünüm & 2 & Koku & 1 & Taşıma & 1 \\
\hline Din & 1 & Kredi Kartı & 1 & Toprak & 1 \\
\hline Doğa & 2 & Kutu & 1 & Tutumlarımız & 1 \\
\hline Elbise & 4 & Kültür & 4 & Ulus & 1 \\
\hline Esirlik & 1 & Künye & 1 & Var Olma & 7 \\
\hline Eş & 1 & Levha & 1 & Vatan & 2 \\
\hline Etiket & 6 & Makine Jakı (giriş bölmesi) & 1 & Yarısı Boş Bardak & 1 \\
\hline Fark & 2 & Maske & 1 & Yaşam Tarzı & 3 \\
\hline Farkındalık & 1 & Meyve & 2 & Yazdığın Yazı & 1 \\
\hline Farklılık & 2 & Nefes & 3 & Yüz & 1 \\
\hline Fitrat & 1 & Nüfus Cüzdanı & 4 & Tanınma & 1 \\
\hline
\end{tabular}

Tablo 6'dan anlaşılacağı üzere kimlik kavramı ile ilgili olarak öğretmen adayları tarafindan 126 farklı metafor geliştirilmiştir. Kimlik kavramında en fazla üretilen metafor "ayna” olmuştur. Aynı sayıda kişiye sorulmasına rağmen kimlik kavramına yönelik üretilen anlamlı metafor sayısının az olmasını, uygulamaya katılan kişiler bu kavramı tam olarak tanımlayamamaları şeklinde açıklamışlardır. Kimlik kavramı için oluşturulan 126 farklı metafor, yapılan açıklamalar doğrultusunda çeşitli kategorilere ayrılmıştır. Bu kategoriler Tablo 7'de gösterildiği gibidir: 
Tablo 7.

Kimlik metaforlart için belirlenen kategoriler ve bu kategorilerin ifade edilme sıkliğl

\begin{tabular}{l|l|l}
\hline Kimlik Metaforu Kategorileri & f & \% \\
\hline Aitlik & 4 & 1,5 \\
\hline Ayırt edici & 25 & 9,6 \\
\hline Değerli & 10 & 3,8 \\
\hline Geçmişi yansıtan & 12 & 4,6 \\
\hline Kapsayıcı & 5 & 1,9 \\
\hline Kişiye özgü & 129 & 49,8 \\
\hline Resmi belge & 9 & 3,5 \\
\hline Sinırlandırıcı & 5 & 1,9 \\
\hline Statü & 11 & 4,2 \\
\hline Şekillendiren & 16 & 6,2 \\
\hline Topluma özgü & 7 & 2,7 \\
\hline Vazgeçilmez & 15 & 5,8 \\
\hline Yön veren & 4 & 1,5 \\
\hline Yanılg1 & 7 & 2,7 \\
\hline Toplam & 259 & 100 \\
\hline
\end{tabular}

Kimlik kavramı için metafor oluşturan 259 öğretmen adayından 129'unun (\%49,8) kimlik tanımı (benzetmesi) kişiye özgü kategorisinde yer almıştır. Bu durum adayların kimliği bireysel bir nitelik olarak gördüklerini göstermektedir. Kategorileri bazında metaforlara yönelik yapılan açıklamaların bazıları şu şekildedir: Kişiye özgü kategorisi:

"Esirlik gibidir, insanın kişiliğin dışına çıkması zordur”(Ö5).

"Koku gibidir, sahibini yansıtır”(Ö26).

"Meyve gibidir, ağacı ne kadar iyiyse meyvesi o kadar olgun olur”(Ö151).

"Endemik bitki gibidir, kişiler arasında farklılık gösterir”(Ö214).

"Kazanımlarımızdır, hayatımız boyunca edindiğimiz özelliklerdir" (Ö3).

Yansitici kategorisi:

"Eş gibidir, kendini başkasında görmedir. Hani insan nasıl düşünürse karşısındakini de öyle görür ya,

bunun gibi bir şey” (Ö56).

“Ayna gibidir, kendini yansıtır" (Ö 8, 17, 33, 52, 57,97, 116, 117) .

- $\quad$ "Ayna gibidir, insanı yansitır"(Ö 175,191).

- Ayna gibidir, hayata bakış açımızı yansıtır" (Ö72).

Yön veren kategorisi:

"Gemi gibidir, dümeni ne yöne çevirirsek o yöne gideriz" (Ö88).

Sinırlandırıcı kategorisi:

- “Anayasa gibidir, bakınca kurallarını görürsün” (Ö236).

- "Tasma gibidir, insanlar günümüzde insanlığın ne olduğunu bilmezler, onlar için kimlik bir tasmadır"

(Ö348).

Kapsayıcı kategorisi:

- $\quad$ "Bilgisayar gibidir, her şeydir"(Ö43).

Değerli Kategorisi:

- "Vatan gibidir, kutsaldır" (Ö122).

\section{Yanılgılar:}

- “Aidiyet gibidir, meşruiyet aracı olması açısından farkındalık kazandırır” (Ö30).

- "Ar1 gibidir, baldan tatlıdır" (127)

- "Bağımsızlık gibidir, benliğimizdir" (Ö329).

- "Kalem gibidir, varsa sen de varsin" (Ö29).

Kimlik kavramına ilişkin oluşturulan kategoriler incelendiğinde dikkat çekici bir sonuç da kimlik kavramına "milli” olarak bakanların sayısının oldukça düşük olmasıdır. Kimlik kavramını "kişiye özgü” olarak tanımlayanların sayısı 259 kişi arasından 129 iken "topluma-millete özgü” olarak tanımlayanların sayısı yalnızca 7 (2,7)'dir. Buradan çıkarılacak bir diğer sonuç "kültür" ve "kimlik" kavramlarını birbirleriyle bağlantılı kavramlar olarak görmemeleridir. Yani katılımcıların büyük bir kısmı "kültürel kimlik" kavramına ya inanmamakta ya da bu iki kavramı birbirinden bağımsız olarak düşünmektedirler. 
Öğretmen adaylarının geliştirmiş oldukları kimlik kavramına ilişkin metaforlar da çeşitli değişkenler açısından incelenmiştir. Bu değişkenlerden cinsiyet değişkenine göre kimlik metaforu kategorileri Tablo 8'de verildiği gibidir.

Tablo 8.

Cinsiyet değişskenine göre kimlik metaforu kategorilerinin dağıllımı

\begin{tabular}{|c|c|c|c|}
\hline \multirow{2}{*}{ Kategori } & \multicolumn{2}{|c|}{ Cinsiyet } & \multirow[b]{2}{*}{ Toplam } \\
\hline & Erkek & Kadın & \\
\hline Aitlik & 2 & 2 & 4 \\
\hline Ayırt Edici & 12 & 13 & 25 \\
\hline Değerli & 5 & 5 & 10 \\
\hline Geçmişi Yansitan & 7 & 5 & 12 \\
\hline Kapsayıcı & 4 & 1 & 5 \\
\hline Kişiye Özgü & 69 & 60 & 129 \\
\hline Resmi Belge & 3 & 6 & 9 \\
\hline Sınırlandırıcı & 2 & 3 & 5 \\
\hline Statü & 5 & 6 & 11 \\
\hline Şekillendiren & 8 & 8 & 16 \\
\hline Topluma özgü & 5 & 2 & 7 \\
\hline Vazgeçilmez & 5 & 10 & 15 \\
\hline Yön Belirten & 2 & 2 & 4 \\
\hline Yan1lg1 & 4 & 3 & 7 \\
\hline Toplam & 133 & 126 & 259 \\
\hline
\end{tabular}

Tablo 8'den anlaşılacağı gibi kategoriler içerisinde en yüksek sayıya sahip olan "kişiye özgü" kategorisi cinsiyet değişkeninde de "kadın (60)/erkek (69)" her iki grupta da en yüksek sayıda çıkmıştır. Birinci sırada yer alan kişiye özgü kategorisini erkeklerde de (12) kadınlarda da (13) "ayırt edici" kategorisi takip etmektedir. Erkek ve kadınlarda oluşturulan metaforlar diğer kategorilerde birbirine çok yakın sayılarda oluşturulmuştur. Ancak "vazgeçilmez" kategorisinde kadınlar tarafindan 10 metafor oluşturulmasına rağmen bu sayı erkeklerde 5 olarak kalmıştır.

Çalışmada kimlik metaforları incelenirken verileri alınan bir diğer değişken ise yaşanılan bölge olmuştur. Tablo 9'da yaşanılan bölge değişkenine göre kimlik metaforuna yönelik oluşturulan kategorilerin dağılımı verilmiştir.

Tablo 9.

Yaşanılan bölge değişkenine göre kimlik metaforu kategorilerinin dağıllımı

\begin{tabular}{|c|c|c|c|c|c|c|c|c|}
\hline \multirow[b]{2}{*}{ Kategori } & \multicolumn{8}{|c|}{ Yaşanılan Bölge } \\
\hline & 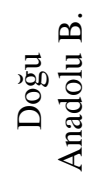 & 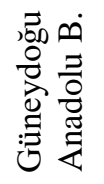 & 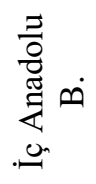 & • & 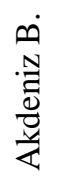 & $\begin{array}{l}\dot{\varphi} \\
\stackrel{0}{\Delta} \\
\Phi\end{array}$ & 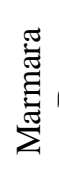 & $\frac{\tilde{\Xi}}{\frac{\tilde{\sigma}}{2}}$ \\
\hline Aitlik & 3 & 0 & 0 & 0 & 0 & 0 & 1 & 4 \\
\hline Ayırt Edici & 15 & 2 & 1 & 0 & 4 & 1 & 2 & 25 \\
\hline Değerli & 5 & 1 & 0 & 1 & 2 & 1 & 0 & 10 \\
\hline Geçmişi Yansıtan & 6 & 3 & 0 & 1 & 2 & 0 & 0 & 12 \\
\hline Kapsayıc1 & 4 & 0 & 0 & 0 & 0 & 0 & 1 & 5 \\
\hline Kişiye Özgü & 77 & 23 & 5 & 13 & 7 & 2 & 2 & 129 \\
\hline Resmi Belge & 7 & 0 & 0 & 2 & 0 & 0 & 0 & 9 \\
\hline Sinırlandırıc1 & 4 & 0 & 1 & 0 & 0 & 0 & 0 & 5 \\
\hline Statü & 6 & 2 & 0 & 1 & 1 & 0 & 1 & 11 \\
\hline Şekillendiren & 10 & 3 & 0 & 0 & 2 & 1 & 0 & 16 \\
\hline Topluma özgü & 2 & 2 & 0 & 2 & 0 & 0 & 1 & 7 \\
\hline Vazgeçilmez & 10 & 3 & 0 & 1 & 0 & 1 & 0 & 15 \\
\hline Yön Belirten & 2 & 0 & 1 & 0 & 0 & 0 & 1 & 4 \\
\hline Yanılg1 & 5 & 1 & 0 & 0 & 0 & 1 & 0 & 7 \\
\hline Toplam & 156 & 40 & 8 & 21 & 18 & 7 & 9 & 259 \\
\hline
\end{tabular}

Tablo 9'a göre de yine en fazla metafor sayısına sahip olan "kişiye özgü kategorisi bütün bölgelerde birinci sırada yer almıştır. Ayrı ayrı bölgeler bazında baktığımızda Doğu Anadolu Bölgesi’nde kişiye özgü kategorisini (77), ayırt edici (15) kategorisi izlemiştir. Bu kategoriden sonra aynı bölgede üçüncü sırayı eşit sayıda 
metaforla "şekillendiren" ve "vazgeçilmez" kategorileri takip etmiştir. Diğer bölgelerde seçilen metaforlar daha homojen dağılmıştır. Bu nedenle dikkat çekici farklı bir veriye ulaşılamamıştır.

Tablo 10'da çalışma için belirlenen diğer bir değişken olan "sınıf" değişkeni verilerine yer verilmiştir.

Tablo 10.

Sinıf değişkenine göre kimlik metaforu kategorilerinin dağılımı

\begin{tabular}{|c|c|c|c|c|c|}
\hline Kategori & $\begin{array}{l}\stackrel{4}{\Xi} \\
\stackrel{\Xi}{二} \\
-\end{array}$ & $\begin{array}{c}\stackrel{4}{\Xi} \\
\stackrel{\sim}{\sim}\end{array}$ & $\begin{array}{c}\stackrel{4}{\Xi} \\
\dot{n} \\
\dot{n}\end{array}$ & 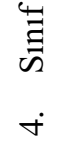 & $\frac{\Xi}{\frac{\Xi}{2}}$ \\
\hline Aitlik & 0 & 0 & 3 & 1 & 4 \\
\hline Ayırt Edici & 8 & 3 & 8 & 6 & 25 \\
\hline Değerli & 2 & 2 & 4 & 2 & 10 \\
\hline Geçmişi Yansitan & 3 & 3 & 4 & 2 & 12 \\
\hline Kapsayıcı & 3 & 1 & 1 & 0 & 5 \\
\hline Kişiye Özgü & 44 & 27 & 45 & 13 & 129 \\
\hline Resmi Belge & 2 & 0 & 4 & 3 & 9 \\
\hline Sinırlandırıcı & 1 & 1 & 3 & 0 & 5 \\
\hline Statü & 5 & 2 & 4 & 0 & 11 \\
\hline Şekillendiren & 7 & 3 & 5 & 1 & 16 \\
\hline Topluma özgü & 1 & 2 & 3 & 1 & 7 \\
\hline Vazgeçilmez & 4 & 1 & 9 & 1 & 15 \\
\hline Yön Belirten & 2 & 0 & 2 & 0 & 4 \\
\hline Yan1lg1 & 2 & 1 & 2 & 2 & 7 \\
\hline Toplam & 84 & 46 & 97 & 32 & 259 \\
\hline
\end{tabular}

Tablo 10'da yer alan verilere göre, bütün sınıflarda "kişiye özgü" kategorisi birinci sırada yer almaktadır. Bu değişkenden elde edilen verilerde, diğer kategorilerde genel olarak sınıflar arasında homojen bir dağılımın olduğu görülmüştür.

\section{SONUÇ, TARTISSMA ve ÖNERILLER}

21. yüzyılda hızlanan kültür ve kimlik değişimi, bu kavramların tarih boyunca sahip olduğu önemi daha da artırmıştır. Öğrencilerin kültür ve kimlik kavramlarına yönelik algılarını teşhis etmeye yönelik gerçekleştirilmiş olan bu araştırmada önemli sonuçlar ortaya çıkmıştır. Her şeyden önce 408 öğrenciden 105 öğrenci $(\% 25,73)$ kültür kavramına yönelik; 149 öğrenci $(\% 36,51)$ ise kimlik kavramına yönelik metafor geliştirememiştir. Öğrencilerin kimlik kavramına yönelik metafor geliştirememedeki sebepleri arasında ya bu kavramın hassasiyeti ya da öğrencilerin kavram hakkında fikir sahibi olmamaları önemli bir ihtimaldir. Gerek bahsedilen dönemdeki siyasi/toplumsal yapının ve gerekse tüm dünyada devam eden hızlı siyasi/toplumsal değişimin söz konusu kavram konusunda zihinlerdeki netliği azalttığı düşünülmektedir. Bu nedenle kültür ve kimlik kavramlarına yönelik algının belirlenmeye çalışıldığı bu çalışma, Tarih, Vatandaşlık, Siyaset Bilimi, İnsan Hakları ve Demokrasi gibi derslerde de öğretmenlere/öğretim üyelerine yol göstermesi açısından önemli olabilir. Söz konusu dersleri veren öğretmenler/öğretim üyeleri bu tür çalışmalar vasıtasıyla derslerinde bu tür kavramlar hakkında zihin bulanıklığını gidermek için kıymetli ipuçlarına ulaşabilirler. Nitekim metaforlar, öğretim uygulamalarını yönlendirmede ve öğretmenlerin modern eğitim anlayışındaki yerlerini belirlemede önemli bir araç konumundadır (Vadeboncoeur \& Torres, 2003, 88). Bu tür araştırmaların benzeri konu veya kavramlar bağlamında yapılarak öğretmenler/öğretim üyeleri için önemli bir kılavuz olabileceği göz önünde bulundurulmalıdır.

Elbette çalışmanın diğer önemli sonuçları öğrenciler tarafından geliştirilen metaforların ortak kategoriler altında toplanması ile ortaya çıkmıştır. Öğrenciler kültür kavramına yönelik 140 farklı metafor geliştirmiştir. Öğrencilerin kültür kavramına yönelik geliştirmiş oldukları metaforlar 13 ayrı kategori altında toplanmıştır. Kültür kavramı için belirlenen kategorilerde en yüksek orana sahip olan kategori 60 metaforla $(\% 19,2)$ "gelişen bir varlık" kategorisi olmuştur. Bu kategoriyi 39 metaforla $(\% 12,8)$ "farklılık" kategorisi, 38 metaforla $(\% 12,5)$ "ortak bir geçmiş" kategorisi izlemiştir. Kültür kavramı için oluşturulan metaforlara değişkenler açısından bakıldığında anlamlı bir fark bulunamamıştır. Benzer bir çalışmada Çelikten (2006) kültür kavramına ilişkin yapmış olduğu çalışmada ilgili literatürü taramış ve literatürden kültür kavramına yönelik olarak elde ettiği metaforları değişim düzenleyicisi, pusula, sosyal yapışkan, kutsal inek, yönetici- kontrollü törenler şeklinde beş kategoride toplamıştır.

Kimlik kavramı kültür, milli değerler, siyasal alan vb. alanlarda farklı tanımlamalara sahip olan bir kavramdır. Yapmış olduğumuz çalışmada "kimlik" kavramı için geliştirilen 126 farklı metafor, 14 kategori altında toplanmıştır. Çalışmamızda 259 öğretmen adayının geliştirdiği metaforların incelenmesinde adayların "kimlik" 
kavramını "milli bir değer" olarak görmedikleri anlaşılmıştır. Ancak Karaçanta'nın (2013) millî değerlere yönelik yaptığı metafor çalışmasında en fazla "kimlik olarak milli değer" kategorisine yönelik metafor geliştirilmiştir. Çalışma bu yönüyle bizim elde ettiğimiz bulgularla ters düşen bulgulara ulaşmıştır.

Çalışmamızda belirlenen 13 kategoride öğretmen adaylarından 129'unun (\%49,8) kimlik metaforu (benzetmesi) "kişiye özgü”" kategorisinde yer almıştır. Bu durum adayların kimliği bireysel bir nitelik olarak gördüklerini göstermektedir. Kimlik metaforunda ikinci sırayı 25 metaforla $(\% 9,6)$ "ayırt edici" kategorisi almaktadır. Bu kavram için geliştirilen diğer kategorilerdeki metaforlar daha homojen bir dağılıma sahiptir.

Öğretmen adaylarının kültür ve kimlik kavramlarına ilişkin geliştirdikleri metaforların incelendiği çalışmamızda her iki kavram için de geliştirilen metaforların bu kavramlara "milli değerler" olarak bakılmadığını göstermiştir. Nitekim kültür metaforu zamanla gelișen, değișen bir varlık olarak görülürken, kimlik metaforu katılımcıların yaklaşık yarısı tarafından bireysel olarak görülmüş ve "kişiye özgü" olması vurgulanmıştır.

Metafor çalışmaları çeşitli kavram, olgu ve olaylara yönelik olarak bireylerin bakış açısı (o kavrama yüklenen anlam), kavram kargaşası/yanılgısı vb. tespit etmek amacıyla kullanılmaktadır. Bu amaçla yapılan metafor çalışmaları, metafor üretilmesi için kullanılan kavrama göre hem eğitsel hem de toplumsal çalışmalarda yol gösterici özelliğe sahiptir. Bu nedenle çalışmanın amacına göre bireylerin temel kavramlara yönelik bakış açısını belirlemek , o çalışmaya konunun hangi kısmından başlanacağı konusunda da araştırmacıya fikir verecektir. Örneğin yapmış olduğumuz çalışmada kültür ve kimlik kavramları incelenmiş ve çeşitli sonuçlara ulaşılmıştır. Bu sonuçlar eğitimcilerin veya sosyologların bu kavramları bireylere anlatırken nelere dikkat etmeleri gerektiği konusunda yol gösterecektir. Bu nedenle araştırılacak ve anlatılacak herhangi bir konu ile ilgili metafor çalışmaları yapmak eğiticilerin işin kolaylaştıracaktır.

Metafor yoluyla özellikle yanılgıların daha fazla yaşandığı kavramların belirlenmesi mümkündür. Bu nedenle özellikle sosyal bilimlerde kültür ve kimlik kavramları gibi ya tam olarak anlaşılmayan ya da bir çok boyutu olan demokrasi, cumhuriyet, kişilik, karakter, yönetim, özgürlük, bağımsızlık gibi üzerine çok yorum yapılan kavramlar için metafor çalışmaları yapılabilir.

\section{KAYNAKÇA}

Arslan, M. \& Bayrakçı, M. (2006). Metaforik düşünme ve öğrenme yaklaşımının eğitim-öğretim açısından incelenmesi. Milli Eğitim Dergisi. 171, 100-108.

Aydoğdu, E. (2008). İlköğretim okullarındaki öğrenci ve öğretmenlerin sahip oldukları okul algıları ile ideal okul algılarının metaforlar (mecazlar) yardımıla analizi. Osmangazi Üniversitesi Fen Bilimleri Enstitüsü, Yüksek Lisans Tezi. Eskişehir.

Balc1, A. (1999). Metaphorical images of school: School perceptions of students, teachers and parents from four selected schools in Ankara. Ortadoğu Teknik Üniversitesi, Yayımlanmamış Doktora tezi.. Ankara.

Cerit, Y. (2008). Öğretmen kavramı ile ilgili metaforlara ilişkin öğrenci, öğretmen ve yöneticilerin görüşleri. Türk Eğitim Bilimleri Dergisi, 33 (147), 3-13.

Çelikten, M. (2006). Kültür ve öğretmen metaforları. Erciyes Üniversitesi Sosyal Bilimler Enstitüsü Dergisi.l (21), 269-283.

Ekiz, D. (2009) Bilimsel araştırma yöntemleri yaklaşım, yöntem ve teknikler. Ankara: Anı yayıncılık.

Karaçanta, H. (2013). Üniversite öğrencilerinin milli değerlere yönelik metaforları. Gazi Üniversitesi Endüstriyel Sanatlar Ë̆itim Fakültesi Dergisi. 32, 107-114.

Koçak, G., Aydın, S. \& Subaşı, M.(2016). Analysis of the perceptions of gifted students on scientist concept through metaphors. British Journal of Education, Society \&Behavioural Science. 17(4), 1-9.

Levine, P. M. (2005). Metaphors and Images of Classrooms. Kappa Delta Pi Record, (4)41, Indianapolis.

Marshall G. (1994/2009). Sosyoloji Sözlü̈̆̈̈u. (Çev. O. Akınhay ve D. Kömürcü). Ankara: Bilim ve Sanat Yayınları.

Morgan, G. (1998). Yönetim ve Örgüt Teorilerinde Metafor. (Çev. G. Bulut). İstanbul: MESS Yayın.

Miles, M. B. \& Huberman, A. M. (1994). An expanded sourcebook: Qualitative data analysis. (Second edition). California: Sage Publications.

Ocak, G. \& Gündüz, M. (2006). Eğitim fakültesini yeni kazanan öğretmen adaylarının öğretmenlik mesleği dersini almadan önce ve aldıktan sonra öğretmenlik mesleği hakkındaki metaforlarının karşılaştırılması. $A K \ddot{U}$ Sosyal Bilimler Dergisi, 8 (2), 293-309.

Oğuz, A. (2005). Öğretmen eğitim programlarında metafor kullanma. XIV. Ĕgitim Bilimleri Kongresi. Pamukkale Üniversitesi. Denizli.

Öztürk, Ç. (2007). Sosyal bilgiler, sınıf ve fen bilgisi öğretmen adaylarının "coğrafya" kavramına yönelik metafor durumları. Kırşehir Eğitim Fakültesi Dergisi. 8 (2), 55-69.

Pektaş, M. \& Kıldan, O. (2009). Farklı branşlardaki öğretmen adaylarının "öğretmen" kavramı ile ilgili geliştirdikleri metaforların karşılaştırılması. Erzincan Eğitim Fakültesi Dergisi. 11 (2), 271-287.

Saban, A. (2004). Giriş düzeyindeki sınıf öğretmeni adaylarının öğretmen kavramına ilişkin ileri sürdükleri metaforlar. Türk Eğitim Bilimleri Dergisi. 2 (2), 131-155. 
Vadebocoeur, J. A. \& Myriam, N. T. (2003). Constructing and Reconstructing Teaching Roles: A Focus on Generative Metaphors and Dichotomies. Discourse: Studies in the Cultural Politics of Education. 24(1), 87-103.

Yıldırım, A. \& Şimşek H. (2011). Sosyal bilimlerde nitel araştırma yöntemleri. Ankara: Seçkin Yayıncılık.

\section{EXTENDED SUMMARY}

Introduction: All sorts of material and spiritual characteristics that a society produces in its historical process and which it has transferred to its origin are called culture. Identity allows one to clearly understand their role and position of a person in society. Living changes also change identity structures because identity is not a fixed one. The values that are effective when the identities are determined lose their significance over time and different values fill their place. When vacant values cannot be substituted, there are situations such as identity crises and identity confusion. These emerging concepts are specific to the 21 st century. Who am I? Which culture do I belong to?" the answers given to the questions began to vary from generation to generation.

In this context, knowing the identities and cultural perceptions of the individuals will make it possible to understand the social structures better. The metaphors developed by the individual in determining the identity and culture perception have a great importance. In recent years, as in the world, in our country, how metaphors guide the activities in the social environment, are examined how they are examined shape their beliefs, attitudes and values and interest in this issue is increasing. For this reason, culture and identity concepts were selected for our research. Aim of study is that university students reveal perceptions about the concept of "culture" and "identity" through their own developed metaphors.

Method: The phenomenology method was used in the study. The sample of the research consists of a total of 408 students, including 138 girls and 270 boys, who were educated in the Social Studies Teaching Program of Kazım Karabekir Education Faculty of Atatürk University in 2013-2014 academic year. Whether there is a relationship between the answers to the relevant metaphors and variables such as "sex, age, class, living area, education level of parents, education and family education" is also examined. But there is no connection between these variables and the answers given to the metaphors of "culture and identity".

Results: In the study, it was seen that 140 metaphors for culture concept and 126 metaphors for identity concept were produced. For the concept of culture, the 140 metaphors created by 303 teacher candidates are classified into 12 categories. These categories are a developing entity, a container, a common past, conservative, indispensable, and reflective form that possesses belonging, distinctive, integrative, value, interaction, differences. For the metaphors produced by 259 prospective teachers, 13 categories were defined as belonging, distinctive, valuable, historical reflecting, containing, personalized, official document, restrictive, status, collecting specific, indispensable, directional shaping.

In the metaphor produced for the concept of culture, it is possible to see the category of "developing entity" with 60 metaphors $(19,2 \%)$ as the highest category. Following this category, there are 39 metaphors $(12,8 \%)$ with a "difference" category and 38 metaphors $(12,5 \%)$ with a "common history" category. According to the gender variable, the most selected category in both male (36) and female (24) students was the category of "developing asset". Equal numbers of metaphors were produced from both groups for the "common past" (19) and "reflective" (11) categories. It is the largest category in terms of gender differences between metaphors and categories has been "value" category. Although boys in this category produce 6 metaphors, 21 girls produced metaphors. In the class variable, the "developing entity" category appears to have received the first rank in the first, second and fourth grades. In the 3rd grade, the first order shares 16 developing metaphorical "being" and "distinctive" categories. While the "value" category ranks second with 14 metaphors in the first grade, the number of students who develop the metaphor for this category in the 4th grade is 1 .

Conclusion And Discussion: Identity definition (analogy) of $129(49,8 \%)$ of the 259 teachers who made metaphor for the concept of identity is in the category of personality. This indicates that prospective teachers see identity as an individual attribute. When the categories related to the concept of identity are examined, it is a remarkable result that the number of those who regard "a national value" as the concept of identity is very low. While the number of people who define the concept of identity as "person-specific" is 129 out of 259 people, only $7(2,7 \%)$ people define it as "collective-national specific". Another conclusion to be drawn here is that they should not regard the concepts of "culture" and "identity" as interrelated concepts. That is, a large part of the participants does not believe in the concept of "cultural identity" or think independently of each other. When the identity metaphor is examined in terms of variables, a remarkable data has not been obtained.

In our study of the metaphors developed by prospective teachers about the concepts of culture and identity, it has been shown that the metaphors developed for both concepts are not regarded as "national values". Indeed, while the cultural metaphor was seen as a changing and developing entity over time, the identity metaphor was seen individually by about half of the participants and emphasized to be "person-specific". 